\title{
Loss of CD20 Expression after Rituximab Therapy for B-Cell Lymphomas: A Review of the Literature
}

\author{
Naoki Wada ${ }^{1} \&$ Katsuyuki Aozasa ${ }^{1}$ \\ ${ }^{1}$ Department of Pathology, Osaka University Graduate School of Medicine, Osaka, Japan \\ Correspondence: Katsuyuki Aozasa, MD, PhD. Department of Pathology, Osaka University Graduate School of \\ Medicine, 2-2 Yamadaoka, Suita, Osaka, 565-0871, Japan. Tel: 81-6-6879-3710. Fax: 81-6-6879-3713. E-mail: \\ aozasa@molpath.med.osaka-u.ac.jp
}

$\begin{array}{ll}\text { Received: April 1, } 2012 & \text { Accepted: May 6, } 2012 \quad \text { Online Published: May 16, } 2012 \\ \text { doi:10.5539/cco.v1n2p1 } & \text { URL: http://dx.doi.org/10.5539/cco.v1n2p1 }\end{array}$

Supported in part by grants (20014012, 20590364, 20014010) from the Ministry of Education, Science, Culture, Sports and Technology, Japan

\begin{abstract}
Rituximab ( $R x)$, a chimeric anti-human CD20 antibody, is used widely for the treatment of B-cell non-Hodgkin's lymphomas (NHL) worldwide. Loss of CD20 expression in relapsed B-cell lymphomas after Rx treatment, however, is observed in some cases, which might be a cause of B-cell NHL unresponsiveness to Rx retreatment. The frequency of loss of CD20 expression after Rx treatment and radiotherapy, its correlation with histological changes, and its clinical implication together with possible molecular mechanisms are discussed in this review of pertinent literature. In high-grade B-cell NHL, loss of CD20 expression after Rx treatment was observed less frequently in Japan than in Australia. Evaluation of CD20 expression by immunohistochemical and flow cytometric methods is a reliable guide for employment of $\mathrm{Rx}$ treatment for B-cell lymphomas.
\end{abstract}

Keywords: B-cell lymphomas, high-grade, low-grade, rituximab

\section{Introduction}

$\mathrm{CD} 20$, a hydrophobic transmembrane protein with a molecular weight of approximately $35 \mathrm{kD}$, is expressed in pre B and mature B lymphocytes (Nadler et al., 1981). Rituximab (Rx) is a chimeric anti-human CD20 antibody that is used widely for the treatment of B-cell lymphomas (Reff et al., 1994) and immune-related diseases, such as rheumatoid arthritis (Edwards et al., 2006). The mechanisms of action of Rx for elimination of non-neoplastic and neoplastic B-cells include antibody-dependent cellular cytotoxicity (ADCC), complement-dependent cytotoxicity, and stimulation of the apoptotic pathway (Reff et al., 1994). Rx was employed originally for the treatment of low-grade B-cell lymphomas or follicular lymphoma (FL). Later, the combined use of Rx with conventional chemotherapy (cyclophosphamide, doxorubicin, vincristine, and prednisone) (Rx-CHOP) was found to be effective for more aggressive diffuse large B-cell lymphoma (DLBCL) (Feugier et al., 2005).

DLBCL, the most common type of malignant lymphoma worldwide, is a diffuse proliferation of large neoplastic B-lymphoid cells. On the basis of gene expression profiles, DLBCL can be categorized into two distinct subtypes: germinal center B-cell (GCB) and activated B-cell (ABC), or non-GCB (Alizadeh et al., 2000). Generally, the non-GCB type is associated with an unfavorable prognosis compared to the GCB type before the employment of Rx therapy.

Positive regulatory domain 1 (PRDM1), a master regulator of the differentiation of mature B lymphocytes into plasma cells, has two isoforms, PRDM1-alpha and -beta, the expressions of which are regulated by the transcriptional regulator NF-kappaB. Using microdissected DLBCL cells, Liu et al. reported that both PRDM1-alpha and -beta were expressed in the non-GCB, but not the GCB, type of DLBCL (Liu et al., 2007). Expression of the PRDM1-beta gene was shown to be correlated with an unfavorable prognosis of non-GCB patients when treated with CHOP, but this was not observed in those undergoing Rx-CHOP treatment (Liu et al., 2007), suggesting a favorable effect of Rx. This same study also reported that B-lymphoma cells resistant to chemotherapy expressed PRDM1-beta, and this expression was suppressed by Rx, possibly through NF-kappaB inactivation. Thus, expression of PRDM1-beta could be a prognostic marker for the non-GCB type of DLBCL. 
Rx-CHOP is now employed as a standard therapy for DLBCL, but recurrence of disease is encountered not infrequently. In such cases, histologic examination of relapsed tumors is not usually performed because DLBCL does not transform to more become more, or less, aggressive. Therefore, reports on the loss of CD20 expression after Rx therapy for B-cell non-Hodgkin's lymphomas (NHL) have been relatively limited.

Tumors occasionally become resistant to therapies that are initially effective. The same phenomenon is observed in B-cell NHL treated with Rx-containing chemotherapy, followed by reduced responsiveness of lymphoma cells to the therapy; loss or reduction of CD20 in lymphoma cells is one cause. In this paper, changes in CD20 expression in B-cell NHL after Rx therapy are discussed with respect to clinical behavior and molecular mechanisms. Davis et al. reported that the response rate of relapsed B-cell NHL to Rx after Rx therapy was less than 50\% (Davis et al., 2000). In such cases, loss of CD20 expression in relapsed B-cell lymphomas could be a robust indicator of resistance to Rx therapy.

\section{Resistance to Rx Therapy in B-cell Lymphomas}

Possible mechanisms of the resistance of B-cell NHL to Rx therapy include three patterns: protection of the tumor cells from Rx-triggered elimination by ADCC / complement-dependent cytotoxicity and apoptotic stimulation, inadequate binding of Rx to the CD20 molecule, and loss of CD20 expression.

\subsection{Antibody-Dependent Cellular Cytotoxicity (ADCC)}

ADCC by natural killer (NK)-cells plays a major role in elimination of B-lymphoma cells during Rx therapy. Rx-induced ADCC was attenuated upon ligation of killer immunoglobulin-like receptors, inhibitory receptors expressed on NK-cells, by human leukocyte antigen (HLA) molecules expressed on human B-lymphoma target cells (Borgerding et al., 2010). Therefore, protection of tumor cells from ADCC by inhibition of NK-cell function through increased HLA expression on tumor cells might explain the failure of Rx treatment for CD20 positive B-cell NHL.

\subsection{Binding of Rx to CD20}

Inadequate binding of Rx to the CD20 molecule might be caused by mutations or polymorphisms of the CD20 gene that affect its structure. However, Sar et al. reported that no mutations were detected in the coding region of the CD20 gene in any of 11 patients with DLBCL who showed a poor prognosis with Rx-CHOP therapy (Sar et al., 2009); one case showed a synonymous single nucleotide polymorphism in exon 2. Johnson et al. reported similar results, demonstrating that mutations of the Rx epitope in the CD20 gene, encompassing exon 5 of the MS4A1 gene, were detected in only one of $264(0.4 \%)$ or one of $15(6 \%)$ biopsies taken at diagnosis or relapse, respectively (Johnson et al., 2009a). No polymorphic sequence variants were detected in this region. Taken together, CD20 mutations involving the Rx epitope are rare in both de novo and relapsed DLBCL.

\subsection{Loss of CD20 Expression after Rx Therapy for B-cell NHL}

Loss of CD20 expression after Rx therapy for B-cell lymphomas is observed as a consequence of purging CD20-expressing B-lymphoma cells. Putative mechanisms are described below.

\subsubsection{Mutations of the CD20 Gene}

Terui et al. reported that deletion mutations in the C-terminus of CD20 were found in 4/50 (8.0\%) cases of B-cell lymphomas; $2 / 22$ cases of DLBCL, 1/7 of FL, 1/1 of mantle cell lymphoma, and 0/20 of other B-cell lymphomas (Terui et al., 2009). This resulted in decreased mean fluorescence intensity of CD20 expression on fresh lymphoma cells compared to cells with non-mutated genes. Three of their $44(6.8 \%)$ patients who had received Rx-CHOP therapy had C-terminal deletion mutations, and they showed progressive disease after Rx-CHOP therapy, suggesting a role for mutation in disease progression. Radiotherapy was employed in two of Terui et al.'s cases before administration of Rx, and deletion of the C-terminus of the CD20 gene and disease progression were found in these cases. Radiation before Rx administration might also cause mutation of the CD20 gene. On the contrary, effects of the CD20 gene sequence on the level of CD20 protein expression were not found in other studies (Tomita et al., 2007; Czuczman et al., 2008). Tomita and colleagues (Tomita et al., 2007) reported epigenetic regulation of CD20 expression in a CD20-negative mature B-cell line, RRBL1, established from a patient treated repeatedly with Rx-containing chemotherapy.

The Gene Scan analysis in our study revealed partial or complete persistence of the same-sized peaks in 11 DLBCL cases, indicating the same origin of tumor cells before and after Rx-containing therapy; however, changes in the peak pattern were also found in many cases, suggesting the presence of genetic instability (Figure 1) (Wada et al., 2009). These findings may explain partly the occurrence of CD20-negative DLBCL after Rx-containing therapy. 

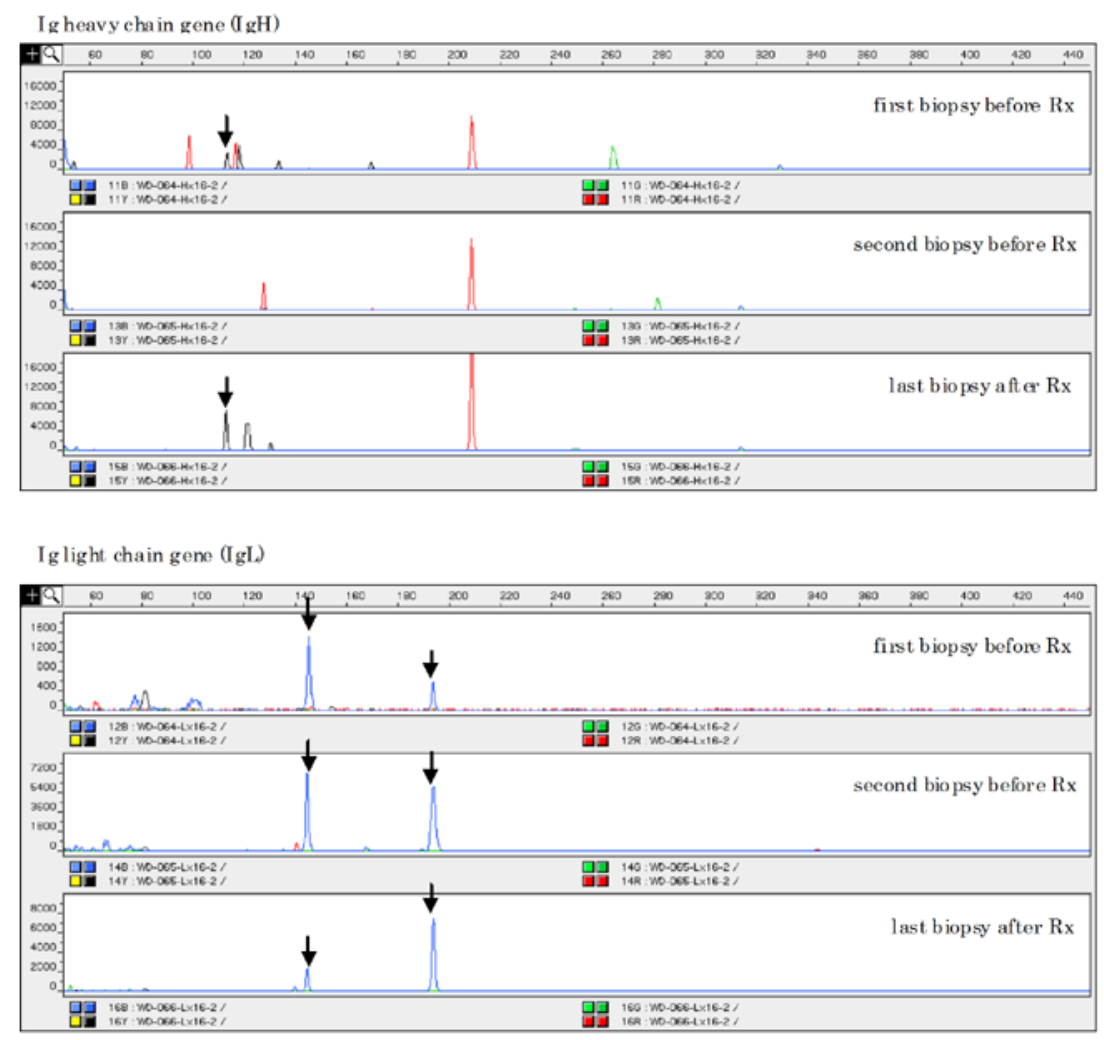

Figure 1. Polymerase chain reaction-based clonality analysis of immunoglobulin (Ig) gene rearrangement (Gene Scan analysis) in a case of diffuse large B-cell lymphoma revealed different peak patterns before and after rituximab (Rx) treatment, with partial persistence of the same-sized peaks $(\downarrow)$

\subsubsection{Immunohistochemical (IHC) and Flow Cytometric (FCM) Analysis}

Johnson et al. reported that tumor cells in 43 of $272(16 \%)$ DLBCL cases showed reduced CD20 expression, 35 of whom also exhibited bright CD19 expression (Johnson et al. 2009b). These 35 cases had a worse prognosis than the other cases with bright CD20 expression when treated with CHOP or Rx-CHOP, irrespective of the international prognostic index. Forty-one of the 43 cases with reduced CD20 expression by FCM showed strong staining for CD20 by IHC. Sequencing of exon 5 of the MS4A1 gene, encoding the extracellular component of the CD20 antigen, did not reveal mutations that could explain the discrepant results between FCM and IHC. Cases showing loss of CD20 expression by FCM, but which were positive for CD20 by IHC, in recurrent tumors of DLBCL after Rx treatment were also reported (Wada et al., 2009; Kennedy et al., 2002); these cases showed progressive disease during Rx-containing therapy. These findings suggest that lack of detection of CD20 by FCM is a sign of resistance to Rx-containing therapy. FCM and IHC analyses detect different epitopes of CD20; extracellular surface epitopes are detected by FCM whereas intracellular ones are detected by IHC. Masking of the surface epitopes through binding of CD20 molecules, instead of gene mutations that affect surface epitopes but preserve intracellular ones, might occur.

\subsubsection{Rx-resistant Cell Lines (RRCL) as a Model for Loss of CD20 Expression}

Tsai et al. reported that rituximab-resistant cell lines (RRCL) exhibited a gradual loss of CD20 surface expression through repeated exposure to Rx (Tsai et al., 2012). They found that the promoter activity of the CD20 gene was decreased, due to reduced binding of several key positive regulatory proteins on the CD20 promoter. Forced CD20 expression restored cytoplasmic, but not surface, CD20, suggesting a defect in CD20 protein transport. Thus, addition of interleukin-4 (IL-4) might induce higher CD20 promoter activity and CD20 expression, improving the responsiveness of RRCL to Rx. 


\section{Clinical Implications of Loss of CD20 Expression in B-Cell Lymphomas after Rx Therapy}

\subsection{Histological Changes and CD20 Expression (Table 1)}

Low-grade B-cell NHL-expressing CD20 might recur as high-grade CD20-negative NHL, which could explain, at least in part, the resistance of recurrent tumors to Rx retreatment (Davis et al., 1999; Schmitz et al., 1999; Alvaro-Naranjo et al., 2003; Maeshima et al., 2009; Hiraga et al., 2009). However, Foran et al. reported that loss of CD20 expression after Rx treatment was not correlated with histological transformation from low-grade to high-grade NHL (Foran et al., 2001).

Table 1. Frequency of loss or significant decrease of CD20 expression after rituximab treatment for CD20-positive B-cell lymphomas

\begin{tabular}{|c|c|c|c|}
\hline & $\begin{array}{l}\text { Frequency of loss or } \\
\text { significant decrease of } \\
\text { CD20 expression (\%) }\end{array}$ & Histological change (case no.) & Authors/Year \\
\hline \multirow[t]{5}{*}{ DLBCL } & $0 / 1(0)$ & NA & Seliem et al/2006 \\
\hline & $4 / 11(36.4)$ & no remarkable change (3) & Maeshima et al/2009 \\
\hline & & proliferation of plasmacytoid cells (1) & \\
\hline & $3 / 7(42.9)$ & NA & Hiraga et al/2009 \\
\hline & $4 / 21(19.0)$ & no remarkable change (4) & Wada et al 2009 \\
\hline \multirow[t]{3}{*}{ MZBCL } & $0 / 2(0)$ & NA & Seliem et al/2006 \\
\hline & $1 / 2(50)$ & proliferation of plasmacytoid cells (1) & Maeshima et al/2009 \\
\hline & $0 / 2(0)$ & NA & Hiraga et al/2009 \\
\hline \multirow[t]{2}{*}{ CLL/SLL } & $3 / 4(75)$ & NA & Seliem et al/2006 \\
\hline & $2 / 2(100)$ & no remarkable change (2) & Maeshima et al/2009 \\
\hline \multirow[t]{5}{*}{ FL } & & no remarkable change (5) & \\
\hline & & proliferation of plasmacytoid cells (2) & \\
\hline & $9 / 34(26.5)$ & transformation to Hodgkin's lymphoma (1) & Maeshima et al/2009 \\
\hline & & $\begin{array}{l}\text { transformation to anaplastic large cell } \\
\text { lymphoma-like undifferentiated lymphoma (1) }\end{array}$ & \\
\hline & $2 / 7(28.6)$ & transformation to DLBCL (2) & Hiraga et al/2009 \\
\hline \multirow[t]{2}{*}{ MCL } & $0 / 10(0)$ & NA & Maeshima et al/2009 \\
\hline & $0 / 1(0)$ & NA & Hiraga et al/2009 \\
\hline LPL & $1 / 1(100)$ & NA & Seliem et al/2006 \\
\hline $\begin{array}{l}\text { Burkitt or } \\
\text { Burkitt-like }\end{array}$ & $0 / 2(0)$ & NA & Hiraga et al/2009 \\
\hline $\begin{array}{l}\text { aggressive } \\
\text { B-NHL }^{*}\end{array}$ & $6 / 10(60)$ & NA & Kennedy et al/2002 \\
\hline B-NHL, NOS & 1/1 (100) & NA & Seliem et al/2006 \\
\hline
\end{tabular}

${ }^{*}$ DLBCL and MCL (mainly DLBCL)

DLBCL indicates diffuse large B-cell lymphoma; MZBCL, marginal zone B-cell lymphoma; CLL/SLL, chronic lymphocytic leukemia/small lymphocytic lymphoma; FL, follicular lymphoma; MCL, mantle cell lymphoma; LPL, lymphoplasmacytic lymphoma; B-NHL, B-cell non Hodgkin's lymphoma; NOS, not otherwise specified; NA, data not available 


\subsection{Transient Loss of CD20 Expression}

Ferreri et al. reported transient loss of CD20 expression in a case of gastric DLBCL after Rx-containing treatment; the tumor cells were initially CD20-positive, turned negative at the first relapse, and restored CD20 expression at the second relapse (Ferreri et al., 2007). Because loss of CD20 expression could be a transient phenomenon, it is meaningful to evaluate $\mathrm{CD} 20$ expression at every relapse of tumors to inform decisions regarding Rx-containing regimens.

\subsection{Frequency of Loss of CD20 Expression after Rx Therapy for Low- and High-Grade B-Cell NHL (Table 1)}

Loss or a significant decrease in CD20 expression was found in various kinds of B-cell NHL and was relatively common in cases with CLL/SLL in previous reports (Seliem et al., 2006; Maeshima et al., 2009). There was no correlation between loss of CD20 expression and interval of biopsies, treatment modalities, clinical response, or frequency and dose of Rx therapy (Maeshima et al., 2009). Jilani et al. reported down-regulation of CD20 expression at the RNA level after exposure of CLL cells to Rx (Jilani et al., 2003). Thus, evaluation of CD20 expression might identify a subset of CLL/SLL patients who will not benefit from repeated therapy with Rx.

Kennedy et al. reported that loss of CD20 expression after Rx treatment was frequently observed in cases of DLBCL, which resulted in progressive disease (Kennedy et al., 2002). A lower frequency, 4 of 21 cases (19\%), of loss of CD20 expression after Rx treatment for DLBCL was reported from Japan (Figure 2) (Wada et al. 2009). The mean Rx dose administered until CD20-negative relapse in the report of Kennedy et al. (5 doses) was lower than that in our cases (9 doses), but the difference was not significant (Wada et al., 2009). The mean time between the last administration of Rx and CD20-negative relapse in the Kennedy et al. cases (5.3 months) was similar to that of our cases (4.5 months).

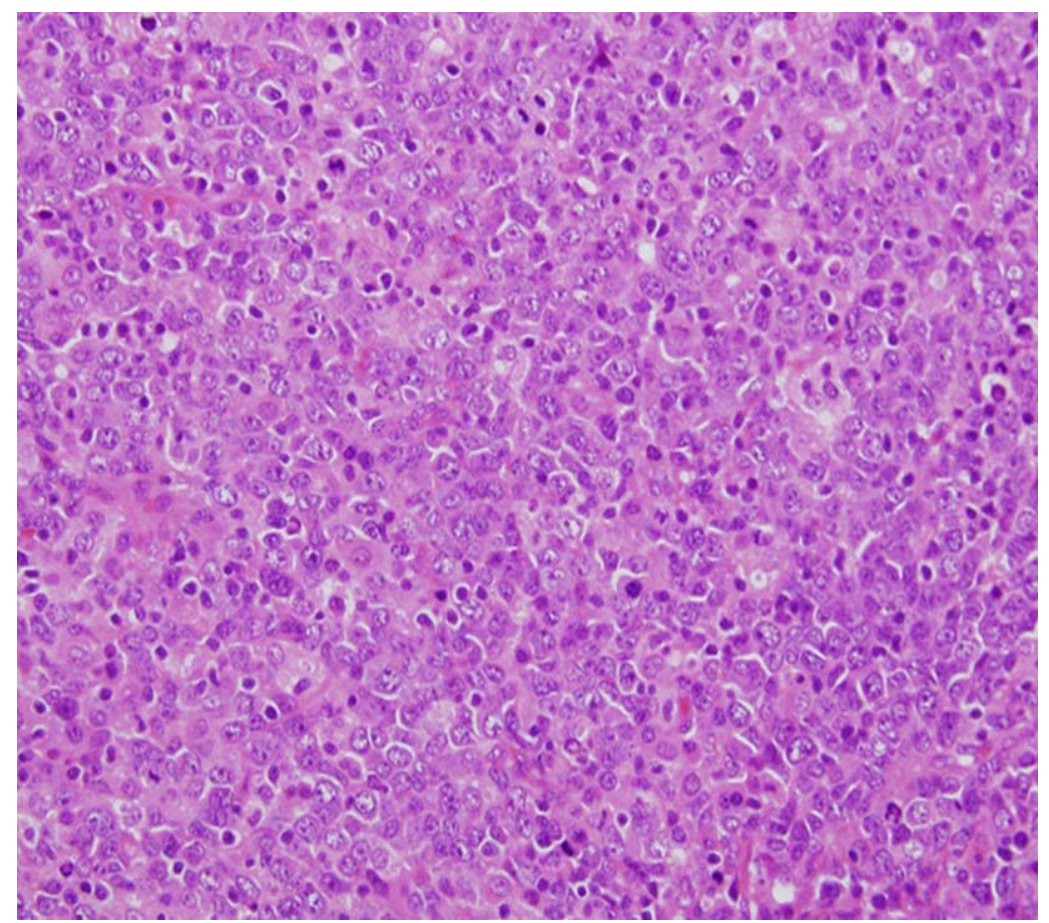

Figure 2. A. Initial diffuse large B-cell lymphoma (DLBCL) (one of our cases). H\&E 


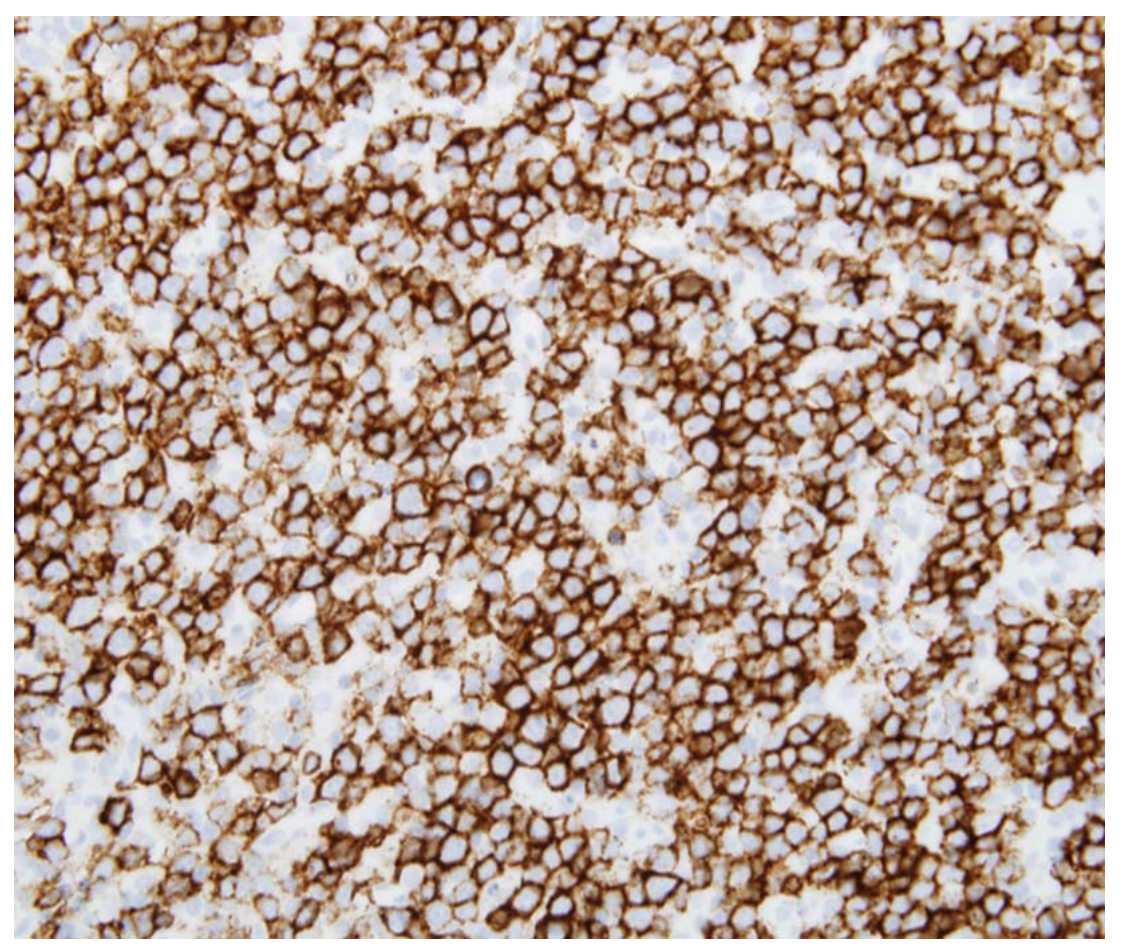

Figure 2. B. Tumor cells were $\mathrm{CD} 20^{+}$by immunohistochemistry

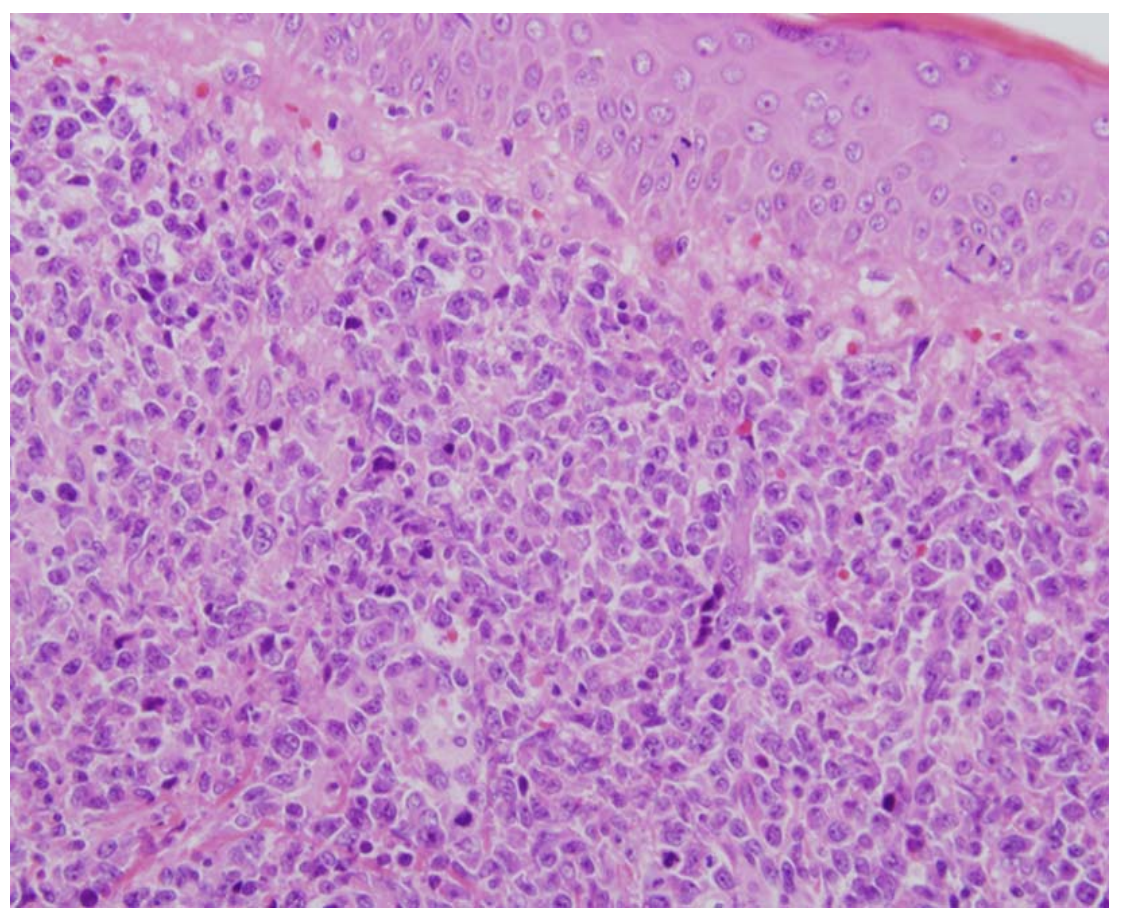

Figure 2. C. Recurrent DLBCL after rituximab treatment showed similar features to the initial DLBCL. H\&E 


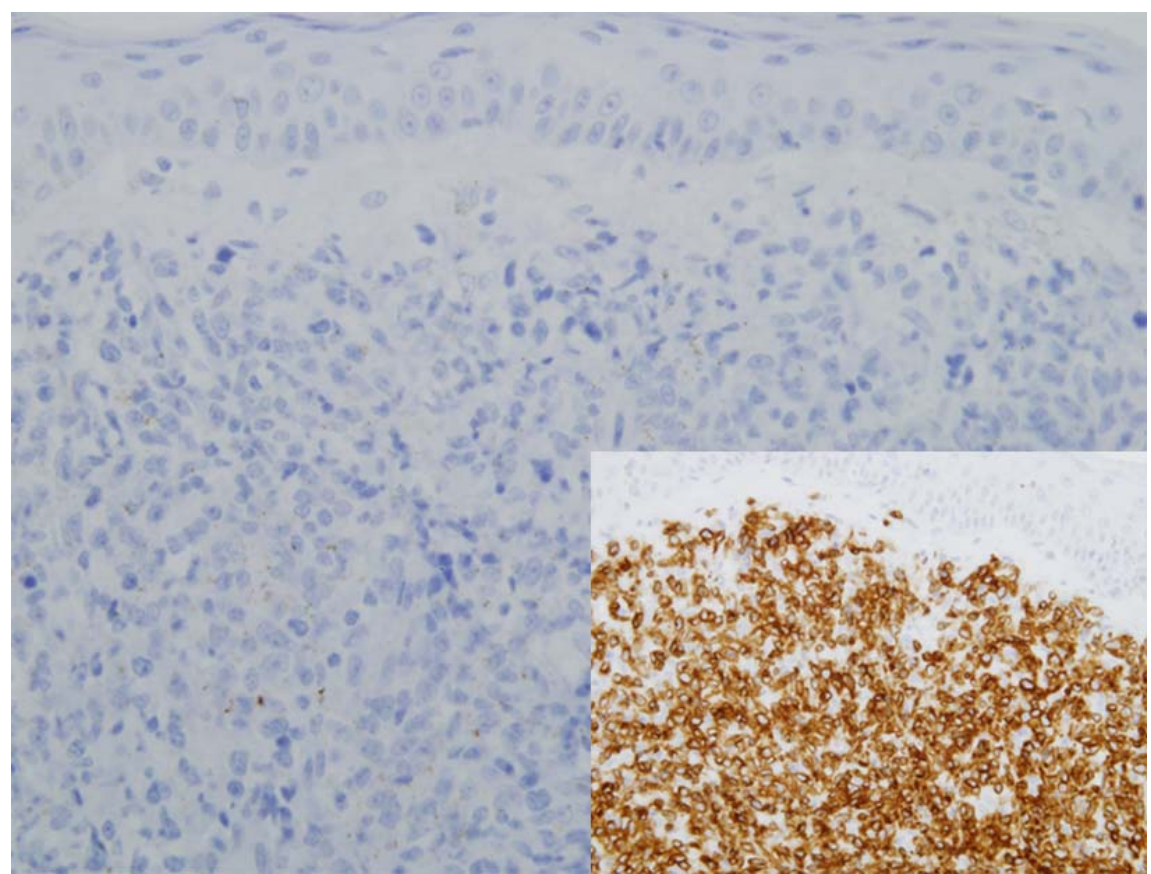

Figure 2. D. Recurrent tumor cells were CD20- Inset: tumor cells were CD79a ${ }^{+}$. Magnification, $x 400$

\section{Conclusion}

Loss of CD20 expression in neoplastic B-cells could be a cause of B-cell NHL unresponsiveness to $\mathrm{Rx}$-containing chemotherapy, which might result in an unfavorable prognosis. Therefore, estimation of CD20 expression is a prerequisite for employment of Rx therapy for B-cell NHL.

\section{References}

Alizadeh, A. A., Eisen, M. B., Davis, R. E., Ma, C., Lossos, I. S., Rosenwald, A., ... Staudt, L. M. (2000). Distinct types of diffuse large B-cell lymphoma identified by gene expression profiling. Nature, 403(6769), 503-511. http://dx.doi.org/10.1038/35000501

Alvaro-Naranjo, T., Jaén-Martínez, J., Gumá-Padró, J., Bosch-Príncep, R., \& Salvadó-Usach, M. T. (2003). CD20-negative DLBCL transformation after rituximab treatment in follicular lymphoma: a new case report and review of the literature. Ann Hematol, 82(9), 585-588. http://dx.doi.org/10.1007/s00277-003-0694-1

Borgerding, A., Hasenkamp, J., Engelke, M., Burkhart, N., Trümper, L., Wienands, J., \& Glass, B. (2010). B-lymphoma cells escape rituximab-triggered elimination by NK cells through increased HLA class I expression. Exp Hematol, 38(3), 213-221. http://dx.doi.org/10.1016/j.exphem.2009.12.007

Czuczman, M. S., Olejniczak, S., Gowda, A., Kotowski, A., Binder, A., Kaur, H., ... Hernandez-Ilizaliturri, F. J. (2008). Acquirement of rituximab resistance in lymphoma cell lines is associated with both global CD20 gene and protein down-regulation regulated at the pretranscriptional and posttranscriptional levels. Clin Cancer Res, 14(5), 1561-1570. http://dx.doi.org/10.1158/1078-0432.CCR-07-1254

Davis, T. A., Czerwinski, D. K., \& Levy, R. (1999). Therapy of B-cell lymphoma with anti-CD20 antibodies can result in the loss of CD20 antigen expression. Clin Cancer Res, 5(3), 611-615. $\mathrm{http}: / /$ clincancerres.aacrjournals.org/content/5/3/611

Davis, T. A., Grillo-López, A. J., White, C. A., McLaughlin, P., Czuczman, M. S., Link, B. K., ... Levy, R. (2000). Rituximab anti-CD20 monoclonal antibody therapy in non-Hodgkin's lymphoma: safety and efficacy of re-treatment. J Clin Oncol, 18(17), 3135-3143. http://jco.ascopubs.org/content/18/17/3135

Edwards, J. C., \& Cambridge, G. (2006). B-cell targeting in rheumatoid arthritis and other autoimmune diseases. Nat Rev Immunol, 6(5), 394-403. http://dx.doi.org/10.1038/nri1838

Ferreri, A. J., Dognini, G. P., Verona, C., Patriarca, C., Doglioni, C., \& Ponzoni, M. (2007). Re-occurrence of the $\mathrm{CD} 20$ molecule expression subsequent to $\mathrm{CD} 20$-negative relapse in diffuse large B-cell lymphoma. Haematologica, 92(1), e1-2. http://dx.doi.org/10.3324/haematol.10255 
Feugier, P., Van Hoof, A., Sebban, C., Solal-Celigny, P., Bouabdallah, R., Fermé, C., ... Coiffier, B. (2005). Long-term results of the R-CHOP study in the treatment of elderly patients with diffuse large B-cell lymphoma: a study by the Groupe d'Etude des Lymphomes de l'Adulte. J Clin Oncol, 23(18), 4117-4126. http://dx.doi.org/10.1200/JCO.2005.09.131

Foran, J. M., Norton, A. J., Micallef, I. N., Taussig, D. C., Amess, J. A., Rohatiner, A. Z., \& Lister, T. A. (2001). Loss of CD20 expression following treatment with rituximab (chimaeric monoclonal anti-CD20): a retrospective cohort analysis. Br J Haematol, 114(4), 881-883. http://dx.doi.org/10.1046/j.1365-2141.2001. 03019.x

Hiraga, J., Tomita, A., Sugimoto, T., Shimada, K., Ito, M., Nakamura, S., ... Naoe, T. (2009). Down-regulation of CD20 expression in B-cell lymphoma cells after treatment with rituximab-containing combination chemotherapies: its prevalence and clinical significance. Blood, 113(20), 4885-4893. http://dx.doi.org/10.11 82/blood-2008-08-175208

Jilani, I., O'Brien, S., Manshuri, T., Thomas, D. A., Thomazy, V. A., Imam, M., ... Albitar, M. (2003). Transient down-modulation of CD20 by rituximab in patients with chronic lymphocytic leukemia. Blood, 102(10), 3514-3520. http://dx.doi.org/10.1182/blood-2003-01-0055

Johnson, N. A., Boyle, M., Bashashati, A., Leach, S., Brooks-Wilson, A., Sehn, L. H., ... Gascoyne, R. D. (2009b). Diffuse large B-cell lymphoma: reduced CD20 expression is associated with an inferior survival. Blood, 113(16), 3773-3780. http://dx.doi.org/10.1182/blood-2008-09-177469

Johnson, N. A., Leach, S., Woolcock, B., de Leeuw, R. J., Bashashati, A., Sehn, L. H., ... Gascoyne, R. D. (2009a). CD20 mutations involving the rituximab epitope are rare in diffuse large B-cell lymphomas and are not a significant cause of R-CHOP failure. Haematologica, 94(3), 423-427. http://dx.doi.org/10.3324/haematol.2008.001024

Kennedy, G. A., Tey, S. K., Cobcroft, R., Marlton, P., Cull, G., Grimmett, K., ... Gill, D. (2002). Incidence and nature of CD20-negative relapses following rituximab therapy in aggressive B-cell non-Hodgkin's lymphoma: a retrospective review. Br J Haematol, 119(2), 412-416. http://dx.doi.org/10.1046/j.1365-2141. 2002.03843.x

Liu, Y. Y., Leboeuf, C., Shi, J. Y., Li, J. M., Wang, L., Shen, Y., ... Zhao, W. L. (2007). Rituximab plus CHOP (R-CHOP) overcomes PRDM1-associated resistance to chemotherapy in patients with diffuse large B-cell lymphoma. Blood, 110(1), 339-344. http://dx.doi.org/10.1182/blood-2006-09-049189

Maeshima, A. M., Taniguchi, H., Nomoto, J., Maruyama, D., Kim, S. W., Watanabe, T., ... Matsuno Y. (2009). Histological and immunophenotypic changes in 59 cases of B-cell non-Hodgkin's lymphoma after rituximab therapy. Cancer Sci, 100(1), 54-61. http://dx.doi.org/10.1111/j.1349-7006.2008.01005.x

Nadler, L. M., Ritz, J., Hardy, R., Pesando, J. M., Schlossman, S. F., \& Stashenko, P. (1981). A unique cell surface antigen identifying lymphoid malignancies of B cell origin. J Clin Invest, 67(1), 134-140. http://dx.doi.org/10.1172/JCI110005

Reff, M. E., Carner, K., Chambers, K. S., Chinn, P. C., Leonard, J. E., Raab, R., ... Anderson, D. R. (1994). Depletion of B cells in vivo by a chimeric mouse human monoclonal antibody to CD20. Blood, 83(2), 435-445. http://bloodjournal.hematologylibrary.org/content/83/2/435

Sar, A., Perizzolo, M., Stewart, D., Mansoor, A., Difrancesco, L. M., \& Demetrick, D. J. (2009). Mutation or polymorphism of the CD20 gene is not associated with the response to R-CHOP in diffuse large B cell lymphoma patients. Leuk Res, 33(6), 792-797. http://dx.doi.org/10.1016/j.leukres.2008.10.013

Schmitz, K., Brugger, W., Weiss, B., Kaiserling, E., \& Kanz, L. (1999). Clonal selection of CD20-negative non-Hodgkin's lymphoma cells after treatment with anti-CD20 antibody rituximab. Br J Haematol, 106(2), 571-572. http://dx.doi.org/10.1046/j.1365-2141.1999.01608.x

Seliem, R. M., Freeman, J. K., Steingart, R. H., \& Hasserjian, R. P. (2006). Immunophenotypic changes and clinical outcome in B-cell lymphomas treated with rituximab. Appl Immunohistochem Mol Morphol, 14(1), 18-23. http://dx.doi.org/10.1097/01.pai.0000145130.02931.74

Terui, Y., Mishima, Y., Sugimura, N., Kojima, K., Sakurai, T., Mishima, Y., ... Hatake, K. (2009). Identification of CD20 C-terminal deletion mutations associated with loss of CD20 expression in non-Hodgkin's lymphoma. Clin Cancer Res, 15(7), 2523-2530. http://dx.doi.org/10.1158/1078-0432.CCR-08-1403

Tomita, A., Hiraga, J., Kiyoi, H., Ninomiya, M., Sugimoto, T., Ito, M., ... Naoe, T. (2007). Epigenetic regulation 
of CD20 protein expression in a novel B-cell lymphoma cell line, RRBL1, established from a patient treated repeatedly with rituximab-containing chemotherapy. Int J Hematol, 86(1), 49-57. http://dx.doi.org/10.1532/ IJH97.07028

Tsai, P. C., Hernandez-Ilizaliturri, F. J., Bangia, N., Olejniczak, S. H., \& Czuczman, M. S. (2012). Regulation of CD20 in Rituximab-Resistant Cell Lines and B-cell Non-Hodgkin Lymphoma. Clin Cancer Res, 18(4), 1039-1050. http://dx.doi.org/10.1158/1078-0432.CCR-11-1429

Wada, N., Kohara, M., Ogawa, H., Sugiyama, H., Fukuhara, S., Tatsumi, Y., ... Aozasa, K. (2009). Change of CD20 Expression in Diffuse Large B-Cell Lymphoma Treated with Rituximab, an Anti-CD20 Monoclonal Antibody: A Study of the Osaka Lymphoma Study Group. Case Rep Oncol, 2(3), 194-202. http://dx.doi.org/10.1159/000249152 